\title{
Evaluation of the Opuntia dillenii as Natural Coagulant in Water Clarification: Case of Treatment of Highly Turbid Surface Water
}

\author{
Yéwêgnon Alima Esther Irma Nougbodé ${ }^{1,2}$, Cokou Pascal Agbangnan², Alain Yaya Koudoro², \\ Comlan Achille Dèdjiho ${ }^{1}$, Martin Pépin Aïna ${ }^{2}$, Daouda Mama ${ }^{1}$, \\ Dominique Codjo Koko Sohounhlouée ${ }^{*}$ \\ ${ }^{1}$ Laboratoire d'Hydrologie Appliquée (LHA), Faculté des Sciences et Techniques, Université d'Abomey-Calavi, \\ Cotonou, République du Bénin \\ ${ }^{2}$ Laboratoire d'Etude et de Recherche en Chimie Appliquée (LERCA), Ecole Polytechnique d'Abomey Calavi (EPAC), \\ Université d'Abomey-Calavi, Cotonou, République du Bénin \\ Email: ksohoun@bj.refer.org, csohoun@gmail.com
}

Received September 13, 2013; revised October 17, 2013; accepted November 14, 2013

Copyright (C) 2013 Yéwêgnon Alima Esther Irma Nougbodé et al. This is an open access article distributed under the Creative Commons Attribution License, which permits unrestricted use, distribution, and reproduction in any medium, provided the original work is properly cited.

\begin{abstract}
This study was performed in laboratory scale and consisted of the using of aqueous Opuntia dillenii solution for the clarification of very turbid surface water (Turbidities varying between 186 NTU and 418 NTU). This plant from Cactaceae family was used as a natural coagulant for the different clarification tests. The preliminary phytochemical Screening of the powder of this plant showed that it contains tanins, saponins and mucilages. Flocculation and coagulation tests showed that Opuntia dillenii can be used in highly turbid water treatment. The removal efficiency varied from $89 \%$ to $93 \%$ for the turbidity and suspended solids, and from $4 \%$ to $15 \%$ for the obvious color in water when we used the optimum values of this natural coagulant $(1 \mathrm{~mL}$ to $10 \mathrm{~mL})$. The successive addition of this natural coagulant and the lime, gave a better elimination of turbidity and suspended solids, and a good reduction for the color. The removal efficiency of the turbidity and suspended solids became more than $95 \%$ and the one of the color between $67 \%$ and $94 \%$.
\end{abstract}

Keywords: Natural Coagulant; Opuntia dillenii; Lime; Phytochemical Screening; Turbidity; Suspended Solids

\section{Introduction}

Surface water contains dissolved organic and inorganic substances, living organisms and suspended solids [1]. These waters intended for human consumption, require a specific sequence of treatments which comprises a physical and/or chemical pretreatment step followed by clarification (coagulation flocculation, sedimentation, and filtration) and finally a disinfection treatment and/or refining treatment.

Processes of coagulation and flocculation represent a decisive step in this processing chain. Coagulant removes small size of suspended solids called colloidal particles that give water undesirable properties such as turbidity, most often caused by clay minerals on which organic substances can be adsorbed. It also removes the color gener-

${ }^{*}$ Corresponding author. ally caused by organic substances such as humic and fulvic acids. The remove of these colloidal particles and color can lead to remove pollutants from water by adsorption and therefore a significant removal of undesirable organic substance, such as trihalomethane precursors $[2,3]$.

The coagulants and flocculants which have the most usage in water treatment are the synthetic ones as aluminium sulphate, ferric chloride, lime, synthetic polymers $[4,5]$. These chemicals are often costly, and may not be available locally, or may have detrimental effects on health and the environment [6].

To overcome these problems, scientific researchers find sustainable alternative technologies using natural coagulants. The seeds of Moringa oleifera are used as natural coagulant for drinking water with better removal efficiency of pollution elements such as turbidity, suspended solids and some metals [7-12]. 
Several other natural flocculants were tested around the world for the water treatment. This is among other things as flocculant extract from Moroccan cactus which has led to a significant reduction of turbidity and the elimination of more than $99 \%$ of chromium (VI) in industrial wastewater [13]. Peels fruits of Lablab purpureus were also used as natural coagulant in water treatment with a yield of $77 \%$ for turbidity [14]. Similarly the use of Plantago ovata and flocculant activity of casein acid extracted from the coconut cream in the clarification of surface water has been demonstrated [15-17]. Some metals such as nickel, iron, zinc, copper, aluminium, chromium and lead, can be removed from the water with a very high efficiency of up to $99 \%$ by use of natural coagulants such as the powder of Moringa seeds, Opuntia ficus indica and many other natural resources [7,18-20].

This study is conducted to expand the range of naturals coagulants used in water clarification in order to increase the chance of access to it, to the population regardless of its geographical position. We chose to use the stems of Opuntia dillenii because of its accessibility in the subregion especially in Benin Republic. The general objective of this work is to clarify highly turbid water using this plant which belongs to the same family than that of Opuntia ficus indica, which has been already experimented in the literature. It will be specifically used in a first step, this natural coagulant for the removal of suspended solids in highly turbid surface water and in a second step, to combine this coagulant with lime to remove the obvious color of the surface water.

\section{Materials and Methods}

\subsection{Plant Materiels}

Cactus (Opuntia dillenii) has been collected in Cotonou town in Benin Republic. The stems of this plant were stripped of their thorns and were cleaned with tap water. A portion was ground immediately for the recovery of the juice for the clarification test. The other part was dried in the laboratory for two weeks and then reduced to powder for phytochemical test.

\section{Preparation of the Opuntia dillenii Aqueous Solution}

The stems of Opuntia dillenii were stripped of their thorns, then washed and crushed; $50 \mathrm{~g}$ of crushed were introduced into $500 \mathrm{~mL}$ of distilled water and stirred using a magnetic stirrer for one hour, then strained through a sieve of $25 \mathrm{~mm}$ mesh. The filtrate collected was stored in a refrigerator until the use which not exceeding one week.

\subsection{Physico-Chemical Parameters Determination}

The $\mathrm{pH}$, conductivity and turbidity were measured respectively using a $\mathrm{pH}$ meter/conductivity meter WTW
$340 \mathrm{i}$ and turbidity meter TURBIQUANT 1100 IR. The color and suspended solids were measured using a colorimeter $\mathrm{HACH} \mathrm{DR} / 890$. The coagulation and flocculation test were conducted using a flocculator LOVIBOND in six stations.

\subsection{Preliminary Phytochemical Screening}

The phytochemical screening was based on the coloring reactions and/or the precipitation reactions of the chemical compounds in plants according to the method described in BAGRE's studies [21] and summarized in table1.

\subsection{Jar Test Experiments (Coagulation Flocculation Test)}

Raw water used for this test was drawn from the Nokoué lake at the lagoon in Abomey Calavi town in Benin Republic. This water was a receptacle of all kinds of discharges due to intense human activity.

The coagulation flocculation was performed according to the protocol of "Jar Test" with rapid mixing of 160 rpm for 2 minutes, followed by slow mixing of $40 \mathrm{rpm}$ for 30 minutes and settling time of one hour. Increasing doses of cactus solution and/or lime were introduced in $1000 \mathrm{~mL}$ of raw water. After settling time, $100 \mathrm{~mL}$ of the supernatant were collected in the average of 2 and $3 \mathrm{~cm}$ from the surface using a pipette and subjected to the same physico-chemical analyzes of the raw water. The removal efficiency of the analyzed parameters was determined by the formula below:

Removal parameter in percentage $=100 \times\left(C_{i}-C_{f}\right) / C_{i}$

$C_{i}$ represents the concentration of the parameter in the raw water.

$C_{f}$ represents the concentration of the same parameter in the treated water.

\section{Results and Discussion}

\subsection{Results of Preliminary Phytochemical Screening}

The results for preliminary phytochemical screening carried out on the Opuntia dillenii's rods powder were shown in Table 1. From these results, Tannins, saponins and mucilages were detected. However, they were devoid of alkaloids, flavonoids and reducing compounds. Results were similar to those of N. Gebresamuel [22]. The presence of mucilages and tannins, conferred to this plant its flocculant property.

\subsection{Results of Jar Test}

The different results obtained are shown in Figures 1-7.

The relationship between the volumes of the Opuntia 
dillenii aqueous solution used as natural coagulant and the removal of turbidity, suspended solids and of the ob-

Table 1. Preliminary phytochemical screening of Opuntia dillenii.

\begin{tabular}{ccc}
\hline Tested for & Specific test/Reagent used & Results \\
\hline Alkaloids & Mayer's reagent, Bouchardat's reagent & $(-)$ \\
Tannins & Ferric chloride Test & $(+)$ \\
Flavonoids & Ferric chloride Test & \\
Reaction with NaOH & $(-)$ \\
Saponins & Froth Test & $(+)$ \\
Mucilages & Test with absolute ether & $(+)$ \\
Reducing compounds & Fehling's test & $(-)$ \\
Quinones & Borntraeger's reagent & $(-)$ \\
\hline
\end{tabular}

$(-)$ absence; $(+)=$ presence.

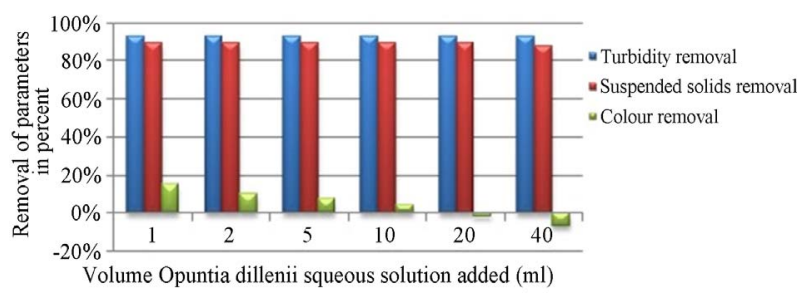

Figure 1. Removal of Turbidity, suspended solids and the apparent color of the treated water according to the volume of Opuntia dillenii aqueous solution added.

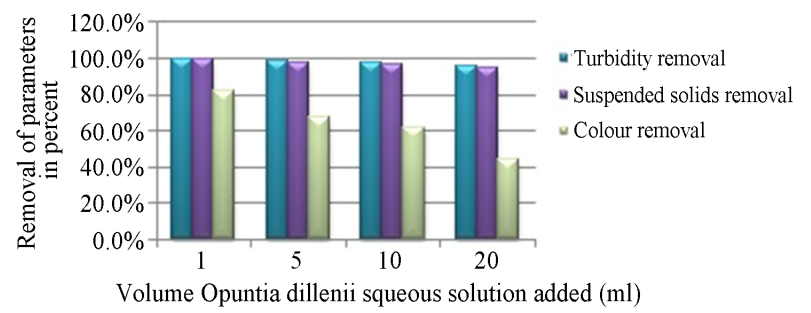

Figure 2. Removal of turbidity, suspended solids and the obvious color of treated water according to the volume of Opuntia dillenii aqueous solution added (concentration of lime remaining fixed: $0.25 \mathrm{~g} / \mathrm{L}$ ).

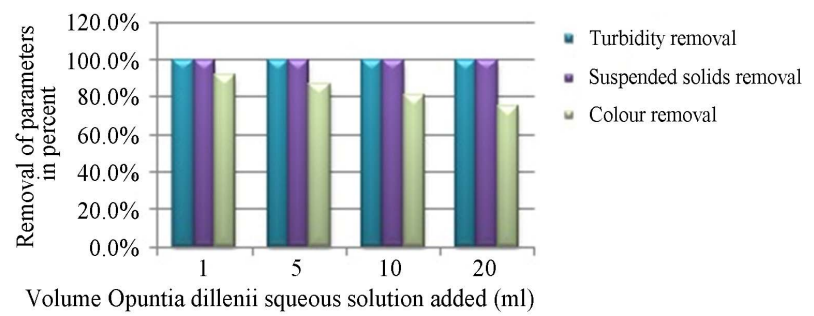

Figure 3. Removal of turbidity, suspended solids and the obvious color of the treated water according to the volume of Opuntia dillenii aqueous solution added (concentration of lime remaining fixed: $0.50 \mathrm{~g} / \mathrm{L}$ ).

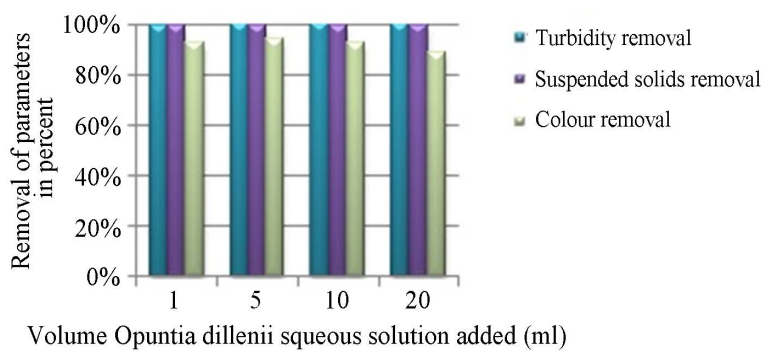

Figure 4. Removal of turbidity, suspended solids and the obvious color of the treated water according to the volume of Opuntia dillenii aqueous solution added (concentration of lime remaining fixed: $1 \mathrm{~g} / \mathrm{L}$ ).

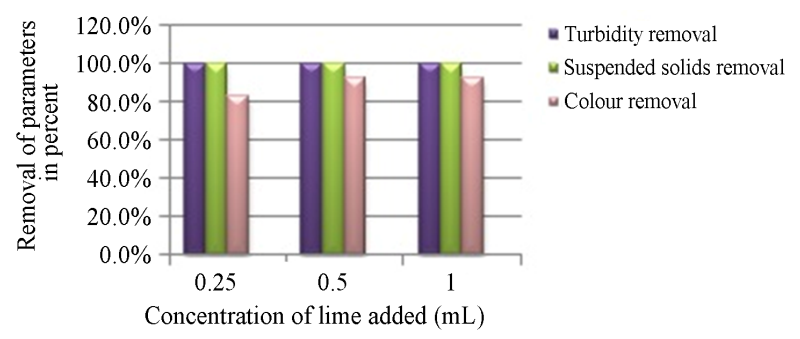

Figure 5. Removal of turbidity, suspended solids and the obvious color of the treated water according to the concentration of lime added (the volume of Opuntia dillenii aqueous solution remaining fixed: $1 \mathrm{~mL}$ ).

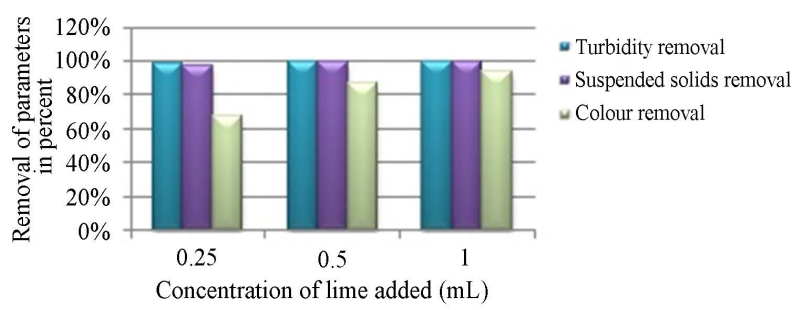

Figure 6. Removal of turbidity, suspended solids and the obvious color of the treated water according to the concentration of lime added (the volume of opuntia dillenii aqueous solution remaining fixed: $5 \mathrm{~mL}$ ).

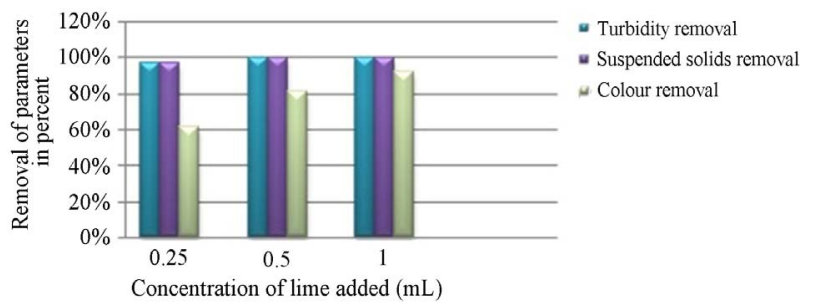

Figure 7. Removal of Turbidity, suspended solids and the obvious color of the treated water according to the concentration of lime added (the volume of the Opuntia dillenii aqueous solution remaining fixed: $10 \mathrm{~mL}$ ).

vious color of the treated water was showed in Figure 1. From these results, it appeared that using only the optimal dosages of this solution (from $1 \mathrm{~mL}$ to $10 \mathrm{~mL}$ ), the removal efficiencies of the obvious color were very low 
(from $4 \%$ to $15 \%$ ) compared to the removal efficiencies of suspended solids and turbidity yields (from $89 \%$ to 93\%). These results were similar to other studies using another species of cactus, Opuntia ficus indica and other natural coagulant to remove turbidity of waters $[14,15]$. Increasing solution Opuntia dillenii from 1 to $40 \mathrm{~mL}$, the removal of the color changed from $15 \%$ to $(-7 \%)$. This removal became negative when adding greater than 20 $\mathrm{mL}$ of volume of this natural coagulant and this meant the value of the color of the treated water was higher than that of raw water. We could deduce that using this coagulant at low dose could slightly reduce the color of the water, but this trend was reversed when it was used at high dose.

Figures 2-7 showed us results of the influence of the combination of lime and Opuntia dillenii aqueous solution on the elimination of parameters studied. From these figures, it appeared that the combination of lime and Opuntia dillenii solution significantly increased not only the removal of turbidity and of suspended solids (>97), but also that of the obvious color which changed from $15 \%$ using Opuntia dillenii solution alone, to $94 \%$ for the optimal combination of this solution with lime. Our results were similar to Abid studies [13], which showed that the optimum value 11 of the $\mathrm{pH}$ provided a good solid-liquid separation hence the increase of performance of the treatment process in terms of suspended solids.

Figures 5-7 showed that, the percentage of color removal increased with the dose of lime. If the volume of natural coagulant was set at $1 \mathrm{ml}$, the removal of color changed from $82 \%$ to $92 \%$ for a concentration of lime ranging between $0.25 \mathrm{~g} / \mathrm{L}$ and $1 \mathrm{~g} / \mathrm{L}$ (Figure 5). Varying the volume of the latter solution at 5,10 , and $20 \mathrm{~mL}$, still for the same variations lime, the removal intervals become respectively $67 \%$ to $94 \%$ (Figure 6) $62 \%$ to $92 \%$ (Figure 7) and $45 \%$ to $88 \%$ (Figure 8). These results showed that even combining it with lime, the increased of Opuntia dillenii aqueous solution always resulted a lower of color removal because this changed from $94 \%$ to $88 \%$ for the adding of $1 \mathrm{~g} / \mathrm{L}$ of lime (Figures 6-8). The performance obtained for suspended solids were similar to those obtained in other studies using Moroccan cactus which botanically is Opuntia ficus indica [13].

\section{Conclusions}

At the end of this study that focused on the use of Opuntia dillenii aqueous solution as a natural coagulant for the waters treatment, we can conclude that the use of this plant helps not only rid this water of suspended solids thereby eliminating turbidity, but its combined action with lime eliminates water color. Our treatment test carried out on the highly turbid water of Nokoué lake in Benin Republic, has shown that $1 \mathrm{~mL}$ of this natural coagulant allows clarifying a liter of this water with a re-

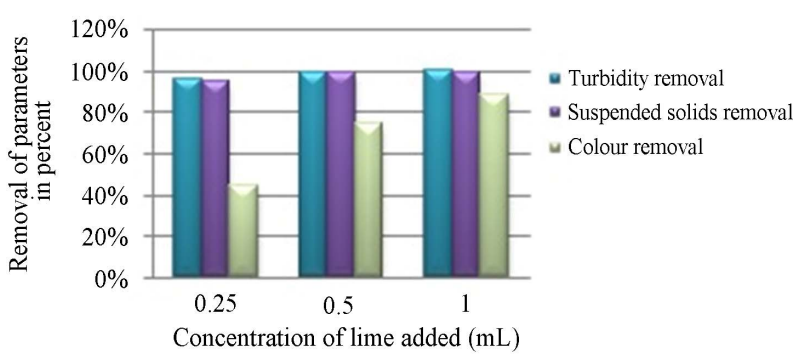

Figure 8. Removal of turbidity, suspended solids and the obvious color of the treated water according to the concentration of lime added (the volume of the Opuntia dillenii aqueous solution remaining fixed: $20 \mathrm{~mL}$ ).

moval of $89 \%$ for the suspended solids, $93 \%$ for the turbidity and $15 \%$ for the color. This same quantity of this natural coagulant used with $1 \mathrm{~g} / \mathrm{L}$ of lime provides better outputs of removal for the parameters studied until $99 \%$ for the suspended solids and turbidity and $89 \%$ for the color.

Opuntia dillenii could be a possible alternative or can display a good role of chemical flocculant or coagulant. It could be more cost-effective for the treatment of the waters and wastewaters especially in our African countries where the economic situation was lackluster.

\section{REFERENCES}

[1] W. J. Masschelein, "Processus Unitaires du Traitement de l'eau Potable," Cebedoc Editeur, Liège, 1996.

[2] E. Lefebvre et B. Legube, "Coagulation par Fe(III) de Substances Humiques Extraites D'Eaux de Surface: Effet du $\mathrm{pH}$ et de la Concentration en Substances Humiques," Water Research, Vol. 24, No. 5, 1990, pp. 591-606. http://dx.doi.org/10.1016/0043-1354(90)90192-9

[3] F. Zidane, K. Cheggari, J. F. Blais, P. Drogui, J. Bensaid and S. I. Ahmed, “Contribution à L'étude de L'Effet de la Coagulation Avant Chloration sur la Formation des Trihalométhanes (THM) et Composés Organohalogénes (COX) dans les eaux Alimentant la ville de Casblanca au Maroc," Canadian Journal of Civil Engineering, Vol. 37, No. 8, 2010, pp. 1149-1156.

http://dx.doi.org/10.1139/L10-065

[4] M. Kim, S. Kim, J. Kim, S. Kang, S. Lee, "Factors Affecting Flocculation Performance of Synthetic Polymer for Turbidity Control," Journal of Agricultural Chemistry and Environment, Vol. 2, No. 1, 2013, pp. 16-21. http://dx.doi.org/10.4236/jacen.2013.21003

[5] D. Zogo, L. M. Bawa, H. H. Soclo et D. Atchekpe, "Elimination de la Couleur et de la Turbidité d'une eau de Surface par Coagulation Floculation au Sulfate D'Alumine: Cas de la Retenue D'Eau de L'okpara en République du Bénin," International Journal of Biological and Chemical Sciences, Vol. 4, No. 5, 2010, pp. 1667-1675.

[6] H. Altaher and A. Alghamdi, "Enhancement of Quality of Secondary Industrial Wastewater Effluent by Coagulation Process: A Case Study," Journal of Environmental Protection, Vol. 2, 2011, pp. 1250-1256. 
http://dx.doi.org/10.4236/jep.2011.29144

[7] J. K. Fatombi, M. G. Josse, V. Wotto and T. Aminou, "Paramètres Physico-Chimiques de l'Eau d'OKPARA Traitée par les Graines de Moringa Oleifera," Journal SOACHIM, Vol. 23, 2007, pp. 75-79.

[8] M. L. Bawa, G. Djaneye-Boundjou, A. G. Soulémane and I. Kpékpassi, "Etude de la Clarification d'une eau de Surface par une Substance Naturelle (les Extraits de Moringa Oleifera Lam): Influence sur la Demande en Chlore," Physical and Chemical News, Vol. 42, 2008, pp. 133-138.

[9] M. Chaudhuri, P. S. Aainaa and B. Khairuldin, "Coagulation-Clarification of Turbid Coloured Water by Natural Coagulation by Naturel Coagulant (Moringa Oleifera) Seed Extrait," Nature Environment and Pollution Technology, Vol. 8, No. 1, 2009, pp. 137-139.

[10] E. N. Ali, S. A. Muyibi, H. M. Salleh, Md. Z. Alam and M. R. M. Salleh, "Production of Natural Coagulant from Moringa Oleifera Seed for Application in Treatment of Low Turbidity Water," Journal of Water Resource and Protection, Vol. 2, 2010, pp. 259-266. http://dx.doi.org/10.4236/jwarp.2010.23030

[11] M. C. Menkiti and O. D. Onukwuli, "Coag-Flocculation of Moringua Oleifera Coagulant (MOC) in Brewery Effluent: Nephelometric Approach," Journal of American Science, Vol. 6, No. 12, 2010, pp. 788-806.

[12] Mu Kheled and Al-Sameraiy, "A Novel Water Pretreatment Approach for Turbidity Removal Using Date Seeds and Pollen Sheath, " Journal of Water Resource and Protection, Vol. 4, No. 1, 2012, pp. 79-92.

[13] Abid, A. Zouhri and A. Ider, "Utilisation d'un Nouveau Bio-Floculant Extrait de Cactus Marocain dans le Traitement des rejets Chargés de Chrome(VI) par le Procédé de Coagulation Floculation," Afrique Science, Vol. 5, No. 3, 2009, pp. 25-35.

[14] B. S. Shilpa, Akanksha, Kavita and P. Girish, "Evaluation of Cactus and Hyacinth Bean Peels as Natural Coagulants," International Journal of Chemical and Environmental Engineering, Vol. 3, No. 3, 2012, pp. 187-191.

[15] G. N. Bidhendi, T. Shahriari and Sh. Shahriari, "Plantago Ovata Efficiency in Elimination of Water Turbidity," Journal of Water Resource and Protection, Vol. 2, 2009, pp. 90-98. http://dx.doi.org/10.4236/jwarp.2009.12013

[16] J. K. Fatombi, M. G. Josse, D. Mama and T. Aminou, "Etude de L'Activité Floculante de la Caséïne Acide Extraite de la Crème de Cocos Nucifera dans la Clarification des eaux de Surface," Revue des Sciences de l'eau, Vol. 22, No. 1, 2009, pp. 93-101.

[17] J. K. Fatombi, J. Mbey, T. Aminou, B. Lartiges, N. Topanou, O. Barres and R. G. Josse, "Flocculation of Kaolinite Suspensions in Water by Coconut Cream Casein," Journal of Water Resource and Protection, Vol. 3, 2011, pp. 918-924. http://dx.doi.org/10.4236/jwarp.2011.312102

[18] Abid, A. Zouhri, A. Ider et S. Kholtei, "Valorisation d'un Nouveau Bio-Floculant Extrait de Cactus Marocain dans le Traitement Physico-Chimique des rejets Liquides Chargés en Cuivre, en Zinc et en Matières en Suspensions," Revue des Energies Renouvelables, Vol. 12, No. 2, 2009, pp. 321-330.

[19] K. R. Raj, A. Kardam, J. K. Arora, M. M. Srivastava and S. Srivastava, "Neural Network Modeling for Ni(II) Removal from Aqueous System Using Shelled Moringa Oleifera Seed Powder as an Agricultural Waste," Journal of Water Resource and Protection, Vol. 2, 2010, pp. 331338. http://dx.doi.org/10.4236/jwarp.2010.24038

[20] P. C. Mane, A. B. Bhosle, C. M. Jangam and S. V. Mukate, "Heavy Metal Removal from Aqueous Solution by Opuntia, a Naturel Polyelectrolyte," Journal of Natural Product and Plant Resources, Vol. 1, No. 1, 2011, pp. 7580.

[21] I. Bagre, C. Bahi, G. Gnahoue, A. J. Djaman and G. F. Guede, "Composition Phytochimique et Evaluation in $\mathrm{Vi}$ tro de L'Activité Antifongique des Extraits des Feuilles de MORINDA MORINDOIDES (BAKER) MILNE-REDHEAD (RUBIACEAE) Sur Aspergillus Fumigatus et Candida Albicans," Journal of Pharma and Bio Sciences, Vol. 8, No. 1, 2007, pp. 15-23.

[22] N. Gebresamuel and T. Gebremariam, "Comparative Physico-Chemical Characterization of the Mucilages of Two Cactus Pears (Opuntia spp) Obtained from Mekelle, Northern Ethiopia," Journal of Biomaterials and Nanobiotechnology, Vol. 3, 2012, pp. 79-86. http://dx.doi.org/10.4236/jbnb.2012.31010 